\title{
Notas de Leitura
}

BRITO, José Maria de. Descoberta de Foz do Iguaçu e a fundação da Colônia Militar. Curitiba-PR: Travessa dos Editores, 2005.

\section{Denise Kloeckner Sbardelotto ${ }^{1}$}

Uma obra inédita e rica em detalhes, a "Descoberta de Foz do Iguaçu e a fundação da Colônia Militar", foi escrita por José Maria de Brito no ano de 1938, quando, já no final de sua vida, se incumbiu de deixar registrado aquilo que presenciou como membro da Expedição Militar designada pela Comissão Fundadora da Colônia Militar do Iguassu, instalada onde hoje se situa a cidade de Foz do Iguaçu, considerada o centro urbano "pioneiro" 2 do Oeste do estado do Paraná. Publicada pela primeira vez em 1938, em tiragem muito pequena - encontramos um exemplar original apenas no Arquivo Público do Paraná -, esta obra é rara e retrata na forma de testemunho parte da história do estado do Paraná e principalmente de sua região Oeste. Foi reorganizada e reeditada no ano de 2005, pela Travessa dos Editores, sob apresentação do jornalista e escritor Beto Maciel e do editor Fábio Campana. Nesta segunda edição foi acrescentado um anexo: a transcrição de um manuscrito de audiências parti-

\footnotetext{
${ }^{1}$ Especialista em História da Educação Brasileira pela Universidade Estadual do Oeste do Paraná - UNIOESTE. Mestre em Educação pela Universidade Estadua de Ponta Grossa - UEPG e Professora Colaboradora nesta mesma Universidade. Membro do Grupo de Estudos e Pesquisa Estado, Educação e Trabalho - GEEPET e do Grupo de Pesquisa em História, Sociedade e Educação no Brasil - GT da Região Oeste do Paraná/HISTEDOPR/UNIOESTE. Áreas de interesse: Fundamentos da Educação; História e História da Educação Regional; História da Educação do Paraná e do Oeste do Paraná.

${ }^{2}$ Os termos "pioneiro (a)", "descobrir" e "descoberta" serão utilizados entre aspas, indicando que nos referimos à ocupação brasileira do século XIX e XX e que não nos valemos de concepções eurocêntricas. Não desconsideramos a legitimidade das ocupações ocorridas em períodos históricos anteriores, incluindo a ocupação indígena do Oeste do Paraná pelos povos Guarani e Caingangue.
} 
culares com colonos da Colônia Militar do Iguassu, datado de 1907, encontrado no Arquivo Nacional do Rio de Janeiro e pertencente aos relatórios do Ministério do Exército.

A história a que se dedica o piauiense José Maria de Brito se confunde com sua própria história de vida. Ele fez parte do Destacamento da Expedição Militar, chefiado pelo $2^{\circ}$ tenente José Joaquim Firmino, e acompanhou todo o penoso percurso da viagem e a fundação da Colônia Militar do Iguassu. Depois da fundação, Brito voltou à cidade de Guarapuava onde foi incumbido de aldear e catequizar índios Guaranis, encontrados durante a Expedição e reunidos em Catanduvas e Formigas. Posteriormente, regressou à Foz do Iguaçu onde exerceu a função de sargento Almoxarife da Colônia Militar do Iguassu e Agente da Companhia de Vapores - La Platense. A seguir, exerceu outros cargos públicos, até mesmo de professor da zona rural do município de Foz do Iguaçu. Nos seus últimos anos de vida José Maria de Brito adoeceu e passou por sérias dificuldades financeiras - em 11 de outubro de 1939, através do Decreto Municipal n. ${ }^{\circ} 4$, Brito passou a receber uma pensão anual, por ser na época o único membro ainda vivo da Expedição que fundou a Colônia Militar do Iguassu. Em Foz do Iguaçu, conheceu uma india, casou-se, constituiu família, fixou raízes e ali faleceu em 1942. É importante observar que a obra de Brito não se caracteriza como um relato de viagem. Ele só se empenhou neste registro muitos anos depois dos fatos vivenciados - há quem diga que a pobreza e o abandono foram os elementos que o impulsionaram a esta tarefa. Como resignado militar que era, Brito o fez também obedecendo ao sentimento de "prestar mais um serviço ao meu país".

No primeiro capítulo, "A fronteira no fim do Império", o autor contextualiza o cenário histórico-político-social dos anos finais do regime Imperial e início do regime Republicano. Explica que a ideia de "descobrir" a foz do Iguaçu, ocupar a região estratégica da tríplice fronteira fundando uma Colônia Militar e construir um forte e uma flotilha ${ }^{3}$ da Marinha

3 Forma de velejar em grupo com outros barcos. 
Nacional já eram assuntos muito discutidos durante os anos finais do Império, mas, por razões politicas, permaneceram por muito tempo no esquecimento.

Três questões foram responsáveis pelo atraso da "descoberta" da foz do Iguaçu: a "Questão Militar", a luta abolicionista e os ideais propagandistas civis-republicanos. Brito afirma que, quando o Exército uniu-se aos abolicionistas e aos civis-republicanos, estes ideais se tornaram mais fortes. Em 1888, quando a "Questão Militar" foi resolvida e João Alfredo Corrêa de Oliveira assumiu o Ministério da Guerra, a classe militar passou a ser vista com bons olhos pelo governo e, com esta harmonia, o estado do Paraná se tornou um terreno mais confortável para as ações do Exército.

No segundo capítulo, "A Expedição", Brito apresenta em riqueza de detalhes a fauna, a flora e os principais acontecimentos durante a longa viagem à foz do Iguaçu. Em 1888, um dos primeiros atos do novo Ministro de Guerra foi a criação de uma Comissão Militar sob o comando do capitão Bellarmino Augusto de Mendonça Lobo. A Comissão tinha uma grande lista de encargos, dentre eles "descobrir a foz do Iguaçu; fundar uma Colônia Militar na mesma foz." Esta Comissão foi oficializada no Rio de Janeiro e enviada à Guarapuava, escolhida para ser a cede por ser o centro urbano mais próximo da região em que os trabalhos seriam realizados. A Comissão compôs uma Expedição Militar, sob o comando do $2^{\circ}$ tenente José Joaquim Firmino e começou seus trabalhos no $\mathrm{Km} 16$ da estrada que ligava Guarapuava à Colônia Militar do Chopim.

É interessante como o autor associa a aventura da Expedição e o papel de Firmino aos grandes feitos da história dos bravos e grandes homens que, tais como Napoleão, Colombo e César, enfrentavam seus medos e todas as adversidades em prol de uma causa nobre. Apesar de a história para ele ser apenas a história dos vencedores, de fato, as adversidades do trajeto foram reais: dias de constantes chuvas, caudalosos e intransponíveis rios, barracas muito pequenas, roupas mofadas, desenvolvimento de bronquites e 
outras moléstias, terrenos acidentados, ataques de tigres e falta de alimentos.

Brito não relata a resistência indígena, mas apenas a colaboração às necessidades da Expedição e se refere a eles como "selvagens", "filhos das selvas", "irmãos das selvas" sob forte influência católica, o que demonstra a união da Igreja ao poder do Exército. Sua concepção era ainda aos moldes jesuíticos: de catequizá-los, civilizá-los e pacificá-los, para que fossem chamados "ao centro da civilização". A obra apresenta apenas vantagens do "grande feito" do Exército ao "descobrir" a foz do Iguaçu - aumento da população, domínio de um ponto estratégico, fonte de rendas, estreitamento de laços de amizade com o Paraguai e a Argentina -, porém não considera os prejuízos que a ocupação brasileira causou aos povos indigenas que ali já habitavam.

No terceiro capítulo, "A Fundação da Colônia Militar", o autor retoma detalhes sobre a longa viagem da Expedição e relata as providências tomadas logo após a "descoberta" da foz do Iguaçu. Recém chegados, após 69 dias de viagem, Firmino tornou público que já havia autoridade na foz do Iguaçu e que esta assumiria a competência de conceder lotes aos colonos interessados - embora esses títulos nunca chegassem às mãos dos colonos. Além disso, Firmino tratou de tomar "providências com o fim de coibir abusos no território descoberto" e avisar que "daquela data por diante não seria mais permitido explorações nas matas brasileiras sem prévia autorização do Governo." Quanto a estes abusos, Brito se referia aos estrangeiros, principalmente argentinos e paraguaios, que durante anos devastaram o Oeste do Paraná com a extração de erva-mate e de madeira. Portanto, a "descoberta" da foz do Iguaçu foi uma iniciativa de salvaguardar a região geograficamente estratégica da tríplice fronteira e tomar a posse efetiva de um território que pertencia legalmente ao Brasil.

Brito se propõe a corrigir erros cometidos por algumas publicações de sua época, em português e espanhol e que, segundo ele, não exprimiam a verdade sobre certos fatos. Cita a questão da data de fundação da Colônia Militar que, 
segundo ele, alguns autores equivocaram-se afirmando ter ocorrido no ano de 1888. Além disso, explica que a Colônia foi instalada em um local diferente do que previam as Instruções devido ao fato de que, diante da seca daqueles meses e a falta de água, os Diretores da Colônia resolveram deslocá-la "provisoriamente" - que acabou sendo definitivo - para um local mais perto da barra do arroio. Os equívocos em relação ao ano de chegada e o local da cidade foram esclarecidos por Brito, entretanto sua narração cai em outras contradições. No segundo capítulo, o autor afirma que a turma exploradora teria chegado ao seu objetivo, à foz do Iguaçu, no dia 15 de julho de 1889 e, no terceiro capítulo, afirma que a Expedição chegou ao Iguaçu em 22 de novembro de 1889! Outro ponto contraditório é em relação à partida da Expedição: no primeiro capítulo Brito afirma que ela teria começado seus trabalhos em 25 de Novembro de 1888 e que os trabalhos anteriores à partida ocorreram em 7 meses e 20 dias. Mas, se foram 7 meses e 20 dias, como Brito pode afirmar, no terceiro capítulo, que a Expedição partiu de Guarapuava em 16 de Setembro de 1889?

Além destas contradições, o livro mostra a versão dos fatos de um ângulo decididamente militar e elitista. Com demasiado saudosismo, a obra enaltece o papel do Exército, cuja presença para o autor era a única garantia de "ordem e progresso". Ao término do terceiro capítulo, Brito apresenta os últimos avanços de Foz do Iguaçu e associa-os às ações do Governo Federal. O faz com um ufanismo característico da década de 1930, típico de um membro militar que vê no retorno do Exército ao poder - a chamada "Revolução de 30" - a possibilidade de renovar suas esperanças patrióticas e de marchar rumo ao progresso.

O manuscrito de audiências particulares do Ministério de Guerra é ainda mais revelador. Mostra os conflitos existentes na Colônia, quem mandava e quem obedecia. Revela que os "negociantes" e extratores de erva-mate e de madeira mais abastados - dentre eles o Coronel Jorge Schimmelpfeng - eram aqueles que decidiam quem permaneceria com lote, quem receberia ajuda ou permaneceria na Colônia. E mais. 
Os "poderosos" economicamente desrespeitavam as leis da Colônia, apossavam-se ou exploravam lotes alheios e não recebiam punição alguma da Diretoria da Colônia.

Apesar das contradições, o livro de José Maria de Brito tem implicações indiretas significativas para pesquisa e para educação na região de Foz do Iguaçu e de todo o Oeste do Paraná. Os materiais bibliográficos desenvolvidos sobre a educação nesta região ainda são escassos, tanto quanto o são os materiais de fontes primárias, documentais e fotográficos. Portanto, as pesquisas no âmbito da Pós-Graduação em história, história da educação e outras diversas áreas, podem encontrar no trabalho de José Maria de Brito uma importante fonte explicativa da gênese da sociedade iguaçuense, que não deixa de exercer influência em todo o território do Oeste do Paraná. Os professores e estudantes de graduação também encontrarão nesta obra uma significativa fonte de pesquisa sobre esta região. Além disso, o texto de José Maria de Brito pode ser explorado em especial nos cursos de licenciatura, nos quais existem orientações no sentido de se conhecer a história do Paraná, para posteriormente ensiná-la nas escolas. Portanto, o ensino da história local nas escolas, principalmente nas séries iniciais do Ensino Fundamental de Foz do Iguaçu, só tem a ser enriquecido considerando os importantes dados registrados por José Maria de Brito.

Trata-se de um único registro existente de um membro fundador da Colônia Militar do Iguassu. É um livro pequeno no tamanho, mas apresenta uma riqueza de detalhes e uma fonte riquíssima para historiadores, pesquisadores, professores e alunos, na medida em que contextualiza - mesmo que de um ângulo tendencioso, militarista e elitista, pois isso não deixa de ser um elemento histórico a ser considerado - o início da história do Município de Foz do Iguaçu e a história do Oeste do estado do Paraná. 